\title{
Caso clínico: Bloqueo del plano del músculo erector espinal para analgesia postoperatoria
}

\author{
Carrasco AJ. ${ }^{1}$, Errigo M. ${ }^{1}$ \\ 1 Hospital Santo Tomás, Panamá, Panamá.
}

Introducción: El bloqueo del músculo erector espinal, propuesto en el 2016 por Forero et al, como una técnica regional que utiliza guía ultrasonografíca, para el bloqueo de las raíces anteriores y posteriores que inervan la pared torácica, primeramente, fue utilizado para el manejo del dolor crónico y agudo en patologías torácicas

El gold standard para manejo del dolor en fracturas costales son infusiones continuas de anestésicos locales, en el espacio epidural, a pesar de esto la evidencia actual apoya el uso de este bloqueo, como una técnica alternativa y sencilla para el manejo del dolor por fracturas costales.

Caso clínico: Paciente de 35 años, con historia de colisión, en vehículo contra objeto fijo, en calidad de conductor, con posterior pérdida de conciencia; trasladado a centro médico de la localidad, donde se intuba y es referido a nuestra institución. Admitido con los siguientes diagnósticos: Trauma múltiple por colisión; Trauma craneoencefálico moderado; Trauma toracoabdominal cerrado. Es llevado al quirófano, para cirugía de control de daños; posteriormente es llevado a cuidados intensivos, permanece por 17 días y luego es manejado por la Unidad de Trauma.

Evolución: En sala de hospitalización se programa para cirugía de fijación de fracturas costales. Preoperatoriamente se coloca catéter epidural para manejo del dolor. Se le realiza una videotoracoscopía + toracotomía + fijación de 3 fracturas desplazadas. En el postoperatorio inmediato con una infusión analgésica epidural, paciente refiere dolor 4/10, de acuerdo a la escala EVA de dolor, en hemitórax izquierdo. A las 24 horas postoperatoria paciente refiere dolor 6/10 que aumenta hasta 8/10, mientras realiza una inspiración forzada, debido a esto se decide realizar bloqueo. Luego de esto paciente presenta mejoría inmediata, refiriendo dolor 3/10, se decide además suspender infusión y retiro de catéter epidural. En sus 48 horas postoperatorias con mayor movilidad, mejor esfuerzo respiratorio y dolor en 2/10. Con alta hospitalaria a los 6 días postoperado.

Conclusión: El bloqueo de plano del músculo erector de la espina es una alternativa analgésica en el manejo del dolor, como en este caso en el cual los métodos tradicionales pueden estar asociados a mayores efectos adversos como hipotensión, neumotórax o formación de hematomas. Su objetivo principal son las ramas que discurren a través de los músculos del erector de la espina. Permite abarcar varios dermatomas con una sola administración. Es una técnica sencilla y relativamente segura en comparación con otras técnicas neuroaxiles.

https://doi.org/10.25237/congresoclasa2019.14 